\title{
Barriers to Inmate Program Participation in a Private Southern US Prison
}

\author{
Kimberly Kaiser \\ University of Mississippi \\ Linda Keena \\ University of Mississippi \\ Alex Piquero \\ University of Miami \& Monash University \\ Caitlin Howley \\ University of Mississippi
}

The Version of Record of this manuscript has been published and is available in the Journal of Crime and Justice, June 30, 2020. Minor differences may exist between this document and the published manuscript. Please cite the manuscript appearing in the Journal of Crime and Justice (http://www.tandfonline.com/DOI: 10.1080/0735648X.2020.1776630).

\section{Author Note}

Correspondence concerning this article should be addressed to Kimberly Kaiser, University of Mississippi, Email: Kakaise1@olemiss.edu. 


\begin{abstract}
Annually, over half a million prisoners are released back into the community. It is important to identify and implement evidence-based strategies within prisons to aid in inmates' re-entry. An impressive knowledge base exists describing the effectiveness of these strategies, but much less is known about the barriers that impede participation in much needed programming. In this paper, we triangulate quantitative and qualitative data obtained from a sample of over 200 state prison inmates in a southern state. Our results show that there is significant interest in many prerelease programs among the inmates, but that several important barriers preclude their participation and/or continuation in these programs. Implications for policy are discussed.
\end{abstract}

Keywords: prisons, prison programs, barriers, participation 


\section{Barriers to Inmate Program Participation in a Private Southern U.S. Prison}

More than 600,000 incarcerated people were released from prison in 2018 in the United States (Carson, 2020)). Ensuring that custodial facilities are well-equipped and staffed to provide evidence-based programming that attend to inmates' needs and skill sets is imperative for increasing the chances of a successful re-entry marked by lessened recidivism (Latessa, 2018). Moreover, it is also critical that inmates can easily access and participate in these programs and that roadblocks to their participation and completion are kept to a minimum. For, if offenders do not envision that their facilities offer programming — or make it easily available — then inmates may become discouraged and not access the types of services that may help them succeed upon release.

There is mounting evidence on the types of programs that are effective among inmates for their skill development, addressing their risk factors, and their ability to help lower the odds of recidivism upon release (Latessa \& Lowenkamp, 2006). Similarly, while private prisons seem able to provide more counseling and educational programs, they also have fewer staff, which could influence the availability and successful delivery of prison programming. On the other hand, much less is known about why inmates choose not participate in programs and their perceived barriers that may prevent motivated inmates from participating.

To help build on this small area of work, the current study uses data from 212 prison inmates in a southern state to examine inmate interest and participation in a variety of programs and, more importantly, the extent to which they perceive barriers - and what those barriers look like - for participating in various programs at the facility. The results of our study offer 
important insight into how prisons may go about increasing program participation and make them more accessible to inmates.

\section{Prison Program Research}

Educational and vocational programs have been mainstays in the American correctional system for over a century. The prison programming serves as an organizing principle for good inmate management (Meyer, Tangney, Stuewig, \& Moore, 2014; Taxman \& Blasko, 2018) and as a rehabilitative tool (Gaes, Flanagan, Motiuk, \& Stewart, 1999; Lawrence, Mears, Dubin \& Trans, 2002; National Reentry Resource Center, 2019). Most research regarding prison programming has focused on whether programs are effective in reducing recidivism (Lee, 2019). For instance, research on participation in educational programs in prisons has been shown to reduce recidivism (Blomberg et al., 2011; Kim \& Clark, 2013; Nally et al., 2012). There is also evidence to suggest that participation in prison programs is linked to improving the chances of finding work upon release (Davis, Bozick, Steele, Saunders, \& Miles, 2013).

Research has also found that most inmates express a desire to participate in prison programs (Neller, Vitacco, Magaletta, \& Phillips-Boyles, 2016). A study by Neller and associates (2016) found that the majority of inmates surveyed were interested in at least one program that was offered at the facility. According to their study, inmates were most interested in programs involving volunteer activities, trade skills, communication skills, and higher education. Inmates were least interested in programs involving substance abuse, aggression, impulse control, and marital dissatisfaction. ${ }^{1}$ The results also indicated that inmates prefer

\footnotetext{
${ }^{1}$ There is an interesting juxtaposition here about specific program interests. In this study, the inmates were interested in more tangible skills but less interested in programs that attend to more interpersonal or individual difference factors - many of which are strongly related to offending.
} 
programs that are both shorter in duration and length, excluding trade skill and education programs.

Yet, while research suggests that most inmates are interested in prison programs, it also indicates that few prisoners actually participate in programs while incarcerated. For example, Eikeland and associates (2016) reported that while interest in educational programs was high $(\sim 73 \%)$, only 43 percent of inmates participated in any educational program. Parsons and Langenbach (1993) found there five factors related to participation in educational programing: personal control, self-assertion, outside contact, self-preservation, and cognitive interest. Similarly, Jackson and Innes (2000) found that inmates who worked full-time prior to incarceration, were more educated, and had less time to serve on their sentence were all more likely to voluntarily participate in programs (Jackson \& Innes, 2000).

\section{Barriers to Inmate Program Participation}

Research on prison programs has predominantly focused on the outcomes of participation and inmate motivations to participate. Research on the barriers faced by inmates that may prevent them from participating in prison programs has only recently been examined. Much of this research has focused exclusively on barriers to educational programs and identified three types of barriers: institutional, situational, and dispositional (Brosens, Croux, \& De Donder, 2019; Manger, Eikeland, \& Asbjørnsen, 2019). For instance, Brosens et al. (2019) found that most inmates who did not participate in educational programs reported situational barriers, such as conflict with work assignments or supervised visitation times. Meyer and associates (2014) found that inmates were challenged with both personal and treatment related barriers. The most common personal barrier related to the cultural stigma associated with participating in treatment programs were common institutional barriers included that they wanted programs that 
were not offered, there was not enough space in program classes, and there was a significant chasm between needed and offered programs.

Much of this research has examined barriers to program participation outside of the United States (e.g., Brosens et al., 2019a; Westrheim \& Manger, 2014; Zhao et al., 2019; cf. Meyer et al., 2014). The United States has a sizable prison population and faces many unique challenges that may present a different context for the study of barriers to prison programs. Additionally, the use of private prisons in the United States deserves added attention. Private prisons tout themselves as a cost-effective solution and reportedly can provide additional counseling and educational programs that government prisons cannot so readily do (Austin \& Coventry, 2001; Lukemeyer \& McCorkle, 2006). Additionally, research has indicated that participation in educational programs is higher in private prisons (Farabee \& Knight, 2002). And yet, while private prisons may fair better in providing programs to inmates, they also face several challenges, such as lack of program staff (Simonds, \& Wright, 2017). For these reasons, the current study extends the research on barriers to inmate program participation in the context of a Southern U.S. private prison.

\section{Methods}

\section{Data Collection Procedure}

Data for this project was collected between February and March of 2019 in a private southern prison with a population of approximately 800 male inmates eligible for prison programs. Inmates in restrictive custody, such as administrative segregation, were not included in this study as they would not be eligible for programming within the facility. The facility houses medium and maximum security inmates. 
Approval to conduct this research was obtained from the Institutional Review Board at the [BLIND FOR PEER REVIEW]. Two days prior to administering the survey, researchers went to each prison unit and read an oral recruitment script outlining the intent and purpose of the study and distributed consent forms to all interested inmates. The consent form described that participation was voluntary and inmates could withdraw at any time. Inmates were assured that their responses would only be available to the researchers and their individual responses would remain confidential and would not be disclosed to prison administration or staff.

The paper-pencil survey was administered in two stages. First, interested inmates from each unit of the prison were brought to the large visitation area to complete the surveys. During this process, researchers once again read the informed consent form and the purpose of the study. In order to increase accessibility, each question on the survey was read aloud by the researchers. Additional research personnel were available to answer any questions or provide clarification. During this stage, all prison staff were asked to sit or stand along the outside of the room so that they were unable to review inmate responses. In this initial stage, 164 surveys were collected. For the second stage of data collection, additional blank copies of the survey along with envelops were left within each unit. Inmates who were unable to attend the in-person sessions were then able to complete the survey on their own time and researchers returned in one week to collect their responses. Inmates placed their completed surveys in a sealed envelope which was placed in a locked box inaccessible to institutional staff. An additional 48 surveys were collected during the second stage of data collection for a final sample size of 212 out of approximately 800 inmates eligible for the study. The response rate was approximately $26 \% .^{2}$ No significant differences were noted between the two groups on demographic characteristics including,

\footnotetext{
${ }^{2}$ According to Fox, Zambrana, and Lane (2011, p.138), researchers should expect to have "anticipated low response rates" when administering surveys to inmates (see also Lane \& Fox, 2013; Ward et al., 2015; Young et al., 2019).
} 
sentence length, marital status, race/ethnicity, and education, as well as on several key variables, such as program participation, program interest, and barriers. There were slight differences between the two groups on age, with the initial sample mean age about four months older than the subsequent sample group. Demographic characteristics of the sample are presented in Table 1. These characteristics closely resemble those of the inmate population at the facility. ${ }^{3}$ Additionally, the demographics of our sample closely match those of the region in which the facility is located.

\section{[Insert Table 1 about here]}

\section{Measures}

Program Interest. Inmates were asked a series of questions to gauge their interest in the variety of programs offered at the facility. The inmates were asked about their level of interest on a 4-point Likert scale $(1=$ not at all interested; $2=$ minimally interested; $3=$ somewhat interested; and 4 = very interested) for 11 types of programs including GED, literacy, substance abuse, culinary, gardening, pre-release, moral cognitive therapy, restorative justice, bible study, and painting or art classes. Inmates were also asked an open-ended question "are there any programs not listed that you would be interested in? Please specify."

Program Participation. Inmates were also asked to report whether they had participated in any of the programs offered at the facility. The programs included in the survey were those listed by the Department of Corrections as programs available to inmates at the facility. This list was then verified with institutional administration and additional classes were added that were offered at the facility but were not as part of the initial list. These were all dichotomous

\footnotetext{
${ }^{3}$ Demographic information of the facility is reported as follows: Average age $=44 ; 75 \%$ African American; $24 \%$ Caucasian; 54\% less than high school diploma; 37\% high school diploma or GED; and 8\% some college. Over 51\% were at facility for five years or longer, $31 \%$ between 1-5 years, and $18 \%$ less than 12 months.
} 
indicators of whether they had participated $(1=$ yes $)$ or not $(0=$ no $)$ in each of the types of programs offered at the facility. Inmates were also provided the opportunity to indicate any additional classes that they had taken while at the facility if not listed. Finally, a composite measure was created representing an index of participation in all types of programs by adding together the number of programs inmates reporting having participated in, ranging from 0 to 8 $($ Mean $=2.39 ; \mathrm{SD}=1.93)$.

Barriers to Inmate Program Participation. Inmates were asked to indicate whether they had experienced barriers to participating in programs at the facility. Inmates were asked to rate on a 4 -point Likert scale $(1=$ not a barrier; 2 = somewhat a barrier; $3=$ moderate barrier; and $4=$ extreme barrier) whether any of the seven issues presented a barrier to their participation. The possible barriers included: lack of space in the program, amount of time to complete the program; pre-requisites to get into the program; program requirements; program not offered often enough; lack of program variety; and prison conditions/circumstances. Inmates were also asked to identify any other barriers not listed. They were also asked a follow-up question to "please elaborate on what factors you found to be a moderate or extreme barrier and why they prevent you from participating in programs. Please give examples."

\section{Analytic Strategy}

The analyses for this study are descriptive in nature and are presented in three stages. First, this study examined the inmate's reported level of interest and participation in various types of prison programs. This was to establish whether there were discrepancies in levels of interest and participation and whether there were unmet needs for prison programming. The second stage examined the quantitative results of the inmate reported barriers that prevent them from participating in prison programs. Finally, this study delved into the qualitative responses to 
provide context and nuance to better understand the inmate reported barriers to prison program participation. Combined, this multi-method exploration into the perceived barriers faced by prison inmates offers unique and important insight to guide the programming features available in this prison and help inform correctional officials about the gaps and challenges for prison programming. As many of these inmates will be released and re-enter the community (Travis \& Petersilia, 2001), offering effective — and evidence-based—programming (and not just the promise of it) is essential for a successful transition and lessen the likelihood of recidivism (Piquero, 2014).

\section{Results}

\section{Program Interest and Participation}

Before we get to the barriers to program participation, it was important to establish whether there is a discrepancy between the level of interest in programs and the amount of participation among inmates. Table 2 presents the descriptive statistics of program interest and the percent of inmates who reported having participated in the programs listed. The breakdown of program interest is also presented in Figure 1. According to Table 2, inmates reported a fairly high interest in programs at the facility, with pre-release programs having the highest average score of 3.51 out of $4(\mathrm{SD}=.91)$. Specifically, $73.6 \%$ of inmates reported being very interested in pre-release programs. This is interesting to note given the high average sentence length of the inmates ( 46 years). Most inmates at the facility were serving life sentences, and yet many were still very interested in pre-release programs, and as will be discussed later, many sought to increase their skill set.

[Insert Table 2 about here]

[Insert Figure 1 about here] 
Subsequent analyses show that inmates across all sentence lengths show a strong interest in pre-release programs. ${ }^{4}$ Specifically, as can be discerned from the 'very interested' column in the cross-tabulations presented in Table 3, on average about $73 \%$ of all inmates expressed significant interest in pre-release programs. On the other hand, $11 \%$ of those individuals whose sentence length was less than 10 years were 'not interested at all', while those inmates serving longer sentence lengths reported much lower percentages of being not interested at all in prerelease programs. ${ }^{5}$ Interest in pre-release programs remains high even for those with multiple years left on their sentence. While pre-release programs clearly demonstrated high interest, inmates also reported the lowest percentage of participation in these types of programs.

[Insert Table 3 about here]

Figure 2 presents the discrepancies between the percentage of inmates that reported being "very interested" in each program type and the percentage that reported having participated in that program. The purpose of this figure is to identify areas of need for specific types of programs. The two areas the facility seemed to meet the need of inmate programs were substance abuse and bible study. However, across all types of programs, the level of inmate interest exceeds the level of participation. As illustrated in this figure, pre-release programs have the highest level of unmet need, followed by culinary and restorative justice programs.

[Insert Figure 2 about here]

\footnotetext{
${ }^{4}$ The three categories of sentence length were created by examining the histogram of length of sentence in months. The inmate population at this facility has a high average sentence length, less than 10 percent of inmates serving less than 10 years, approximately $16.5 \%$ serving $10-19$ years and the majority $(74.53 \%)$ serving 20 years or longer. ${ }^{5}$ Additional analyses were conducted using time left on sentence instead of sentence length. Results from this analysis did not substantially differ from those presented in Table 3.
} 


\section{Barriers to Inmate Program Participation}

As the previous section demonstrated, there is a high level of interest among inmates for prison programs, we next examine what factors may limit inmate participation. In this section, we explore various barriers, as reported by inmates, that prevent them from participation in programs at the facility. Table 4 presents the means of each type of barrier reported.

[Insert Table 4 about here]

According to Table 4, prison conditions or circumstances received the highest rating as a barrier, averaging 2.82 out of $4(\mathrm{SD}=1.17)$. While the category of "other" also reported as a relatively high barrier $($ Mean $=2.62 ; \mathrm{SD}=1.51)$, only 88 inmates responded to the "other" category. Almost $40 \%$ of the inmates reported that prison conditions or circumstances were an extreme barrier to program participation, with an additional $22.22 \%$ reporting it a moderate barrier. This was followed by the lack of variety of programs offered, with almost $44 \%$ reporting that as either a moderate or extreme barrier, and the program pre-requisites, with $43.75 \%$ of inmates reporting it as either a moderate or extreme barrier. Few inmates felt that the amount of time to complete the program or program requirements were a barrier to their participation.

Table 5 presents the correlations between program participation and the inmate identified barriers to participation. As shown, four inmate identified barriers are negatively correlated with the number of programs an inmate has participated in. Specifically, the higher an inmate reported there to be a lack of space in the program $(\mathrm{r}=-.23, p<.01)$, the program not being offered enough $(\mathrm{r}=-.18, p<.05)$; the requirements of the program $(\mathrm{r}=-.12, p<.10)$, and the prerequisites to get into the program $(r=-.17, p<.05)$ the fewer number of programs an inmate had reported participating in. Table 5 also demonstrates that there is a high level of correlation between all inmate identified barriers. 
[Insert Table 5 about here]

\section{Qualitative Responses to Barriers to Program Participation}

After reviewing the quantitative reports of barriers preventing program participation, we sought to delve more deeply into the qualitative responses to gain a better understanding as to why these were barriers to program participation. Inmates were asked to "elaborate on what factors they found to be a moderate or extreme barrier and why they prevent you from participating in programs." Of the 212 inmates, $171(80.66 \%)$ provided qualitative responses to this question. We were able to categorize 165 responses. The remaining six responses were either not descriptive enough to accurately categorize or specified "no barrier." We used an open and axial coding strategy based on a grounded theory approach to identify themes within the responses (Strauss \& Corbin, 1990). First, each response was read carefully several times to identify common terms and concepts. Next, we used axial coding to provide context and compare the open codes with each other to identify relevant categories or themes. Through this process, we identified five themes present within the inmate reported barriers to prison program participation. Table 6 presents the results of the qualitative analysis. Name Voyager (2020) was used to assign pseudonyms. When possible, we provide the general age, race, and sentence length of the inmates providing the specific quotes. For some inmates, this information was unavailable or revealed more precise information that may unintentionally identify specific inmates.

[Insert Table 6 about here]

Theme 1: Prison Conditions Barriers. Barriers related to prison conditions were present within 62 of the inmates' responses. The majority of these, about 79\%, mentioned the adverse impact that frequent lockdowns had on their ability to participate in prison programs. 
Many inmates noted that the frequent lockdowns at the institution resulted in them being unable to finish programs on time. As noted by David (30-40 years old, African American), "Due to lock downs it is hard to complete classes sometimes which is a factor for parole date deadlines."

Issues of frequent lockdowns and security were often tied together as a barrier to prison program participation. Some inmates expressed that the frequent lockdowns and security issues hindered their ability for self-improvement. As Jaden, a 40-50 year old African American inmate, reported "Security and institution being placed on lock down because of contraband being found on certain offenders, these institutional lockdown with the group punishments hinders the offenders that are trying to better themselves." This concern also related to issues of security within the facility. As another inmate, Samuel (30-40 year old, African American), stated "Some classes lag do security and often times graduations is set off holding up the next class. Constant lockdowns are counterproductive to any educational programs."

Inmates also noted that the facility lockdowns reduced morale and interest in program participation. Stephan, a 30-40 year old African American inmate, expressed that "This facility has no reliable system. Maybe for a week or 2 straight we go to our classes and then all of a sudden were on lock down because of lack of staff or some other issue.” Relatedly, several inmates noted issues with lack of movement and lockdowns interrupting programs, disrupting their ability to participate. Specifically, Randy (40-50 year, Caucasian) noted that "Movement rule/lockdowns and things seem to go on every other day that stops class from taken place" and another (40-50 years old) illustrated how count can disrupt programs when he said “... the security schedule and count times that prevent school scheduled from being followed."

Theme 2: Staffing Issues. A theme closely related to prison conditions as a barrier to prison program participation was the issue of staffing within the facility. Many inmates noted 
that the cause of the frequent lockdowns was not due to inmate behavior, but instead to a lack of staff. A lack of staff or staffing concerns were present within 29 of the inmate responses. As noted by a 40-50 year old, African American participant:

You can never finish class on time, if it's 1 year it will take 1 year 3 or 4 months to finish due to lock down or lack of officers. They either get fired or quit contraband get bought in...

Often, this lack of staffing would result in classes being canceled for weeks at a time. As illustrated by Carlos (20-30 year old, Caucasian), "The staff here they use short of staff excuse a lot. They cancel a lot of stuff because of it. We don't have class a lot just recently. We didn't have class for 2 or 3 weeks."

Theme 3: Eligibility and Access Issues. Another theme that was common within the inmate reported barriers to program participation were issues related to eligibility and program access. According to the respondents, many of them were restricted from participating in programs because of the amount of time left on their sentence. Several inmates serving life sentences, for example, noted that "if you have life, many of the programs are not available to you." It is unclear whether inmates believed they were not eligible to participate in programs or whether those that had less time left were given priority for the limited program space, as was noted by one inmate (40-50, Asian) "Because I am serving a life sentence and inmates with a lot of time are put on the back burner." After seeing this theme recurring, we contacted the facility to inquire whether there was a policy prohibiting those serving life sentences from participating in programs. We were told that there was no such policy. It is clear, however, that many inmates believe that "... if you have a life sentence they will not let you take some classes." This theme is 
rather surprising given that the majority of the inmates at the facility were serving lengthy or life sentences.

Inmates also reported that they were prohibited from participating in some programs because of their crimes or charges. For example, Thomas (30-40 year old, Caucasian) noted, "I found it hard to take some classes because of my prison charge." Another inmate, James, illustrated both concerns of program restriction based on crime of conviction and length of time left on sentence, stating "You cannot participate in culinary arts if you have a set crime. You have to have short time or be court ordered for alcohol and drugs and many people need help." Michael (60-70 year old African American) eloquently expressed how this particular restriction affects him when he said "The charge a person has or time shouldn't prevent that person from learning, it only make's that person believe that there is prejudice against his crime or how much time he or she has."

Issues of selection and prerequisites were also noted as barriers to program participation. Several inmates expressed concerns about how inmates were chosen for programs, noting that they believed this process to be unfair. Ricky (20-30 year old, Caucasian) expressed his concerns with the selection process by saying:

Some programs must "know somebody" or play kiss ass to be a part of. Even then, certain criteria such as time/amount of sentence remaining, as well as the charge one is convicted of or plead to, can cause one to be marginalized from placement in program and/or job placement. If the message being sent is jobs in prison itself require not to be charged with this or with that certain theory (?), what kind of hope does that leave in a man's mind for opportunities he or she may get in the "free world". Being denied entry to certain jobs or programs in prison can lead people to question their true value, their worth 
in general. Can lead to feelings of hopelessness based on the "what if" scenarios of what if they won't let me work in maintenance or medical here in prison, how will I ever get a job upon release?

Several inmates expressed that the selection process to get into programs was not fair, noting that “if you don't know somebody it's hard to get in any class you want to be in" (60-70 year old, Caucasian) and that "They seem to use favoritism in the choices of participants" (50-60 year old, African American). Richard, however, noted that his victimization at another prison limited his access to programs at the current facility:

I was a victim of rape at [redacted] prison, and so the fact that I was a victim I cannot be in the same class as "another predator or victim" as they say. So I was told that I have to get corporate in [redacted] to approve for me to just even get into class "any class".

Theme 4: Program Quality Issues. Although not as frequent as the other noted barriers, the inmates expressed some concerns relating to program quality as barriers to participation. These largely were issues relating to the lack of experience or quality of the instruction or quality of the program generally. Alfonzo noted that "The quality and effectiveness of the programs offered are poor because they don't certify you at a skill or trade that you can reenter society with and maybe help better your choices at gaining employments." Other inmates commented specifically on the quality of instruction by noting "Job placement can be a lot better some instructor have very poor people skills don't know how to talk to you when you are just ask a question.” Enrique (30-40 year old, Caucasian) stated:

Mentors and instructors allow personal feelings of inmates to keep them out of class or keep them from helping them. Or are just not qualified to teach the class. Some just don't care because they are over worked and under paid especially the case manager. 
Theme 5: Variety and Availability Issues. Forty-one inmates commented that the lack of space in programs, lack of availability of programs, and lack of variety were barriers to their participation in prison programs. Many inmates expressed a need for vocational or career programs. As illustrated by Ralph (40-50 years old, Caucasian):

Not enough actual life skill/workplace programs that give you a trade to enter into workforce upon release. Lack of space meaning it is very hard to get into this program. Secondly, we not given enough time in program to fully absorb teachings. Other inmates noted the lack of availability of the programs that were offered. In the words of Dameon (30-40 years old, African American), "On the times listed it is always or most always full with no definite date on when or how the availability works." Others said "For there being 1,000 inmates only 15-25 allowed to be in class" and "Classes may be full and we may have to wait for months." Some inmates noted that they have already taken advantage of the programs offered and wanted a larger variety of opportunities, "Because I've taken every class already and I'm ready for more. I need to learn some trade skills."

\section{Discussion and Conclusion}

Given the more than 600,000 inmates who are released back into the community each year (Carson, 2000), there has been a concerted focus on attempting to provide services for inmates while institutionalized in order to better prepare them for their eventual reentry and with the hope that these programs help to reduce the high levels of recidivism that exist for exprisoners. In fact, there is an impressive array of studies that have sought to evaluate the kinds of services provided to prisoners, which ones are the most effective, and which ones are not (see Www.crimesolutions.gov). While cataloging the effectiveness of prison programs is important, 
we think that an equally important topic worth investigating is the extent to which inmates perceive barriers to participating in these programs. For if they perceive that access to such programs is somehow limited or otherwise unavailable, then inmates may not seek out needed programs and training to help increase their likelihood of a prosocial entry back into society. Unfortunately, the issue of inmate perceived barriers to prison programming is under researched. Our study sought to add to this body of research with a sample of inmates serving lengthy sentences in one southern private prison.

Three key findings emerged from our mixed method analysis. First, the inmates expressed a high level of interest in prison programming, especially surrounding pre-release programming, a finding that was especially unexpected for inmates serving life. This is not surprising as inmates are seeking help for the transition back into the community as well as obtaining tangible skill sets as shown by the high level of interest in computer and culinary classes. It was also interesting to find that the inmates also participated in a great range of programs including substance abuse and moral cognitive therapy programs, perhaps recognizing that these are key risk (and protective) factors that are implicated in the reasons why many individuals offend.

Second, when asked to report on the barriers that they perceived to inhibit participation in programming, the inmates highlighted prison conditions/circumstances, the lack of variety, and pre-requisites to get into the program as the most common. Third, and relatedly, our qualitative data provided a more detailed explanation about these perceived inhibitors that culminated in five overall themes: (1) prison conditions, (2) staffing issues; (3) eligibility/access, (4) program quality issues; and (5) variety/availability. More specifically, many inmates noted that constant lockdowns resulted in training not being offered or cut short, thereby delaying time to 
graduating. Other inmates commented on the manner in which they are able to access and participate in the programs, with some inmates erroneously believing that longer sentences made some ineligible for programming and others commenting on the overall culture not just of the prison structure but also about some of the correctional staff who do not seem interested in helping the inmates or did not engage in a fair process for providing programs to inmates. Further, inmates commented on the availability of some programs, with a lack of variety and limited choices being common concerns.

At one level, these results are encouraging. Inmates, even those who are serving lengthy or even life sentences, were interested in prison programming to acquire skill sets or help improve their ability to successfully re-enter society by accumulating important trade experiences. On the other hand, some of the results are disconcerting. Although desiring programming, many inmates reported barriers to their ability to participate in the programs. Many of these, it seems, can be attended to including, offering a more diverse set of programs, identifying and addressing the conditions that underlie the frequent lockdowns that inhibit prison programming, and ensuring that inmates know what programs they are eligible for while institutionalized. Other barriers surrounded the climate of the institution which is shaped in large part by the culture of the prison as demonstrated by staff behavior. On this point, several inmates reported that correctional staff were not very interested in helping inmates with programming and to the extent that this creates negativity within inmates about 'bettering' themselves, then the prison culture could have even more harmful, indirect effects on the potential for successful reentry. In the end, it is imperative that prisons do a better job at identifying the specific needs that inmates have and then funneling them into the programs that are tailored to those needs. 
Implementation and adherence to the risks-needs-responsivity (RNR) model is imperative for successful re-entry and lower recidivism.

Some limitations with our study need to be highlighted. First, as with many correctional surveys (for similar response rates, see: Fox et al., 2011; Lane \& Fox, 2013), the response rate was low, thereby obscuring the extent to which the inmates who chose not to report are somehow different from those who did with respect to the questions addressed in our study. We are pleased that the inmate demographics of the overall prison was very similar to the demographics of our sample, but we cannot definitively rule out any selection effects. Second, our sample was obtained from a private prison and the extent to which the results would be similar (or different) in public prisons in the state in question or others remains to be investigated. Lastly, our sample was comprised of a large set of inmates who were serving very lengthy or even life sentences. While we did examine inmate perceptions among those inmates serving shorter sentences, it would be useful to examine these issues with different types of prisons. This is especially important since our data were drawn from a single private prison housing medium and maximum security inmates. The extent to which our findings hold in different types of facilities with a different makeup of inmates is an open question.

Our analysis shows that inmates desire important programming while in prison, they participate in many which are critical for helping to increase the odds of a successful re-entry, but they also perceived many barriers to their participation. Successful re-entry helps exoffenders and the community where to/in which they are released. With respect to policy proscriptions, we see two specific points which emanate from our work. The first is to ensure that adequate evidence-based programming is available to inmates and that such programs are delivered by trained staff and with high fidelity. Doing so is paramount to helping inmates 
increase their chances of success and lessen their likelihood of recidivism. And funding and scaling up of such programs and ensuring that inmates are matched to specific programs and encouraged to participate is critical. Secondly, it is imperative that prison management, including leadership at the Department of Corrections, encourage a climate among staff that is positive in that, in addition to holding offenders accountable for their crimes, inmates are matched to the kinds of programming that is helpful and aids re-entry. With a positive staff culture and a climate conducive to effecting change, staff may find that inmates' behavior is not marked by negativity but instead by a relationship that is built on trust and legitimacy. Corrections staff, and the climate they espouse, can learn from parallel lessons in the policing field, where key issues are those related to trust and legitimacy. Encouraging these two concepts within prison walls may help to develop more legally socialized persons outside those same walls. This approach has been found to stimulate more prosocial -and less antisocial—behavior (Fagan \& Piquero, 2007). 


\section{References}

Austin, J., \& Coventry, G. (2001). Emerging issues on privatized prisons (NCJ 181249). Washington, DC: U.S. Department of Justice, Office of Justice Programs/Bureau of Justice Assistance.

Name Voyager (2020). Baby name voyager. Retrieved from https://www.babynamewizard.com/voyager\#prefix=\&sw=both\&exact=false

Blomberg, T. G., Bales, W. D., Mann, K., Piquero, A. R., \& Berk, R. A. (2011). Incarceration, education and transition from delinquency. Journal of Criminal Justice, 39(4), 355-365.

Brosens, D., Croux, F., \& De Donder, L. (2019a). Barriers to prisoner participation in educational courses: Insights from a remand prison in Belgium. International Review of Education, 65(5), 735-754. https://doi.org/10.1007/s11159-018-9727-9

Brosens, D., De Donder, L., Dury, S., \& Verté, D. (2015). Barriers to participation in vocational orientation programmes among prisoners. Journal of Prison Education and Reentry, 2(2), 8-22. https://doi.org/10.15845/jper.v2i2.817

Carson, A. (2020). Prisoners in 2018. Washington DC: Bureau of Justice Statistics. Retrieved from: https://www.bjs.gov/index.cfm?ty=pbdetail\&iid=6846

Davis, L. M., Bozick, R., Steele, J. L., Saunders, J., \& Miles, J. N. V. (2013). Evaluating the effectiveness of correctional education. A meta-analysis of programs that provide education to incarcerated adults. Santa Monica, CA: RAND Corporation. Retrieved 6 March 2017 from http://www.rand.org/ pubs/research_reports/RR266.html.

Eikeland, O., Manger, T., \& Asbjørnsen, A. (2009). Prisoners' educational backgrounds, preferences and motivation: Education in Nordic prisons. Copenhagen: TemaNord. 
Eikeland, O. J., Manger, T., \& Asbjørnsen, A. E. (2016). Utdanning, arbeid, ønske og planar [Education, work, wishes and plans]. Bergen: Fylkesmannen i Hordaland, Utdanningsavdelinga.

Fagan, J., \& Piquero, A.R. 2007. Rational choice and developmental influences on recidivism among adolescent felony offenders. Journal of Empirical Legal Studies, 4, 715-748.

Farabee, D., \& Knight, K. (2002). A comparison of public and private prisons in Florida: During- and post-prison performance indicators. Los Angeles: Query Research.

Fox, K., Zambrana, K., \& Lane, J. (2011). Getting in (and staying in) when everyone else wants to get out: 10 lessons learned from conducting research with inmates. Journal of Criminal Justice Education, 22(2), 304-327.

Gaes, G. G., Flanagan, T. J., Motiuk, L. L., \& Stewart, L. (1999), Adult correctional treatment. Crime and Justice, 26, 361-426.

Jackson, M. L., \& Innes, C. A. (2000). Affective predictors of voluntary inmate program participation. Journal of Offender Rehabilitation, 30(3-4), 1-19.

Kim, R. H., \& Clark, D. (2013). The effect of prison-based college education programs on recidivism: Propensity score matching approach. Journal of Criminal Justice, 41(3), 196204.

Lane, J., \& Fox, K. A. (2013). Fear of property, violent, and gang crime: Examining the shadow of sexual assault thesis among male and female offenders. Criminal Justice and Behavior, 40(5), 472-496.

Latessa, E.J. 2018. Does treatment quality matter? Of course it does, and there is growing evidence to support it. Criminology \& Public Policy, 17, 181-188. 
Latessa, E.J., \& Lowenkamp, C. 2006. What Works in Reducing Recidivism?, University of St. Thomas Law Journal, 3, 521-535

Lawrence, S., Mears, D. P., Dubin, G., \& Travis, J. (2002). The practice and promise of prison programming. Retrieved from: http://webarchive.urban.org/publications/410493.html

Lee, L. M. (2019). The impact of prison programming on recidivism. Corrections: Policy, Practice and Research, 4(4), 252-271.

LoBuglio, S. (2001). Time to reframe politics and practices in correctional education. Retrieved from: https://files.eric.ed.gov/fulltext/ED508715.pdf

Lukemeyer, A., \& McCorkle, R. C. (2006). Privatization of prisons: Impact on prison conditions. American Review of Public Administration, 36(2), 189-206. https://doi.org/10.1177/0275074005281352

Manger, T., Eikeland, O. J., \& Asbjørnsen, A. (2019). Why do not more prisoners participate in adult education? An analysis of barriers to education in Norwegian prisons. International Review of Education, 65(5), 711-733.

Meyer, C. L., Tangney, J. P., Stuewig, J., \& Moore, K. E. (2014). Why do some jail inmates not engage in treatment and services? International Journal of Offender Therapy and Comparative Criminology, 58(8), 914-930.

Nally, J., Lockwood, S., Knutson, K., \& Ho, T. (2012). An evaluation of the effect of correctional education programs on post-release recidivism and employment: An empirical study in Indiana. Journal of Correctional Education, 63(1), 69-89.

National Reentry Resource Center (2019). Integrated reentry \& employment strategies: Pilot project process evaluation report. Retreived from https://csgjusticecenter.org/wpcontent/uploads/2019/10/FINAL-IRES-Pilot-Project-Proc-Eval-Report.pdf 
Neller, D. J., Vitacco, M. J., Magaletta, P. R., \& Phillips-Boyles, A. B. (2016). Eliciting responsivity: Exploring programming interests of Federal inmates as a function of security classification. International Journal of Offender Therapy and Comparative Criminology, 60(4), 423-434.

Parsons, M., \& Langenbach, M. (1993). The reasons inmates indicate they participate in prison education programs: Another look at boshier's PEPS. Journal of Correctional Education, 44(1), 38 .

Piquero, A.R. 2014. Moving From Description to Implementation of Evidence-Based Research Findings. Criminology \& Public Policy 13, 127-134.

Simonds, R., \& Wright, K. A. (2017). Private prisons. The Encyclopedia of Corrections, (August 2017), 1-4. https://doi.org/10.1002/9781118845387.wbeoc149

Taxman, F. S., \& Blasko, B. (2018). Policy and program innovations in prisons. In J. D. Wooldredge, \& P. Smith (Eds.), The Oxford handbook of prisons and imprisonment (pp. 669-687). New York, NY: Oxford University Press.

Travis, J., \& Petersilia, J. (2001). Reentry reconsidered: A new look at an old question. Crime \& Delinquency, 47(3), 291-313.

Westrheim, K., \& Manger, T. (2014). Iraqi prisoners in Norway: Educational background, participation, preferences and barriers to education. Journal of Prison Education and Reentry, 1(1), 6-19. https://doi.org/10.15845/jper.v1i1.593

Zhao, Y., Messner, S. F., Liu, J., \& Jin, C. (2019). Prisons as schools: Inmates' participation in vocational and academic programs in chinese prisons. International Journal of Offender Therapy and Comparative Criminology, 63(15-16), 2713-2740. https://doi.org/10.1177/0306624X19861051 


\section{Inmate Report Barriers to Program Participation}

Table 1.

Demographic Characteristics of the Inmate Sample $(n=212)$

\begin{tabular}{|c|c|c|c|}
\hline Characteristics & Mean or $\%$ & SD & Range \\
\hline Age & 44.82 & 11.90 & $20-73$ \\
\hline \multicolumn{4}{|l|}{ Race/Ethnicity } \\
\hline Black & 60.1 & & \\
\hline White & 27.9 & & \\
\hline Other & 22.0 & & \\
\hline Hispanic & 4.88 & & \\
\hline \multicolumn{4}{|l|}{ Marital Status } \\
\hline Single (never married) & 46.3 & & \\
\hline Married/Domestic Partnership & 20.2 & & \\
\hline Widowed & 5.4 & & \\
\hline Divorced & 28.1 & & \\
\hline \multicolumn{4}{|l|}{ Education } \\
\hline Less than HS diploma & 26.5 & & \\
\hline HS diploma or GED & 42.6 & & \\
\hline Some college & 20.6 & & \\
\hline College degree & 10.3 & & \\
\hline \multicolumn{4}{|l|}{ Length of Time at Facility } \\
\hline Less than 1 month & 5.3 & & \\
\hline 1-6 months & 11.5 & & \\
\hline 7-12 months & 5.3 & & \\
\hline $1-5$ years & 32.2 & & \\
\hline 5 years or more & 45.7 & & \\
\hline Average sentence length (in years) & 46.41 & 30.64 & 15 months - life ${ }^{*}$ \\
\hline
\end{tabular}

Note: *Sentences capped at 960 months, or 80 years. 
Table 2.

Inmate Interest and Participation in Programs

\begin{tabular}{lcccc}
\hline \multirow{2}{*}{ Program Interest } & \multicolumn{2}{c}{ Level of Interest } & & Participation \\
\cline { 2 - 3 } GED programs & 3.04 & SD & & Percent \\
Literacy programs & 2.98 & 1.18 & 33.88 \\
Substance Abuse & 2.94 & 1.24 & & 13.66 \\
Culinary Classes & 3.39 & .96 & 44.26 \\
Computer Classes & 3.35 & .97 & 15.30 \\
Pre-Release Programs & 3.52 & .91 & 36.07 \\
Moral Cognitive Therapy & 3.28 & 1.02 & \\
Restorative Justice & 3.41 & .93 & 37.83 \\
Gardening Classes & 3.03 & 1.14 & 17.48 \\
Bible Study & 3.31 & 1.05 & 12.57 \\
Painting or Art Classes & 2.79 & 1.18 & 45.90 \\
\hline
\end{tabular}

Note. Level of Interest is a 4-point Likert scale ranging from $1=$ Not at all Interested to $4=$ Very Interested. Participation is a dichotomous measure on whether the inmate had participated in that type of program $(0=$ no; 1 $=$ yes). 
Figure 1.

Inmate Interest in Prison Programs

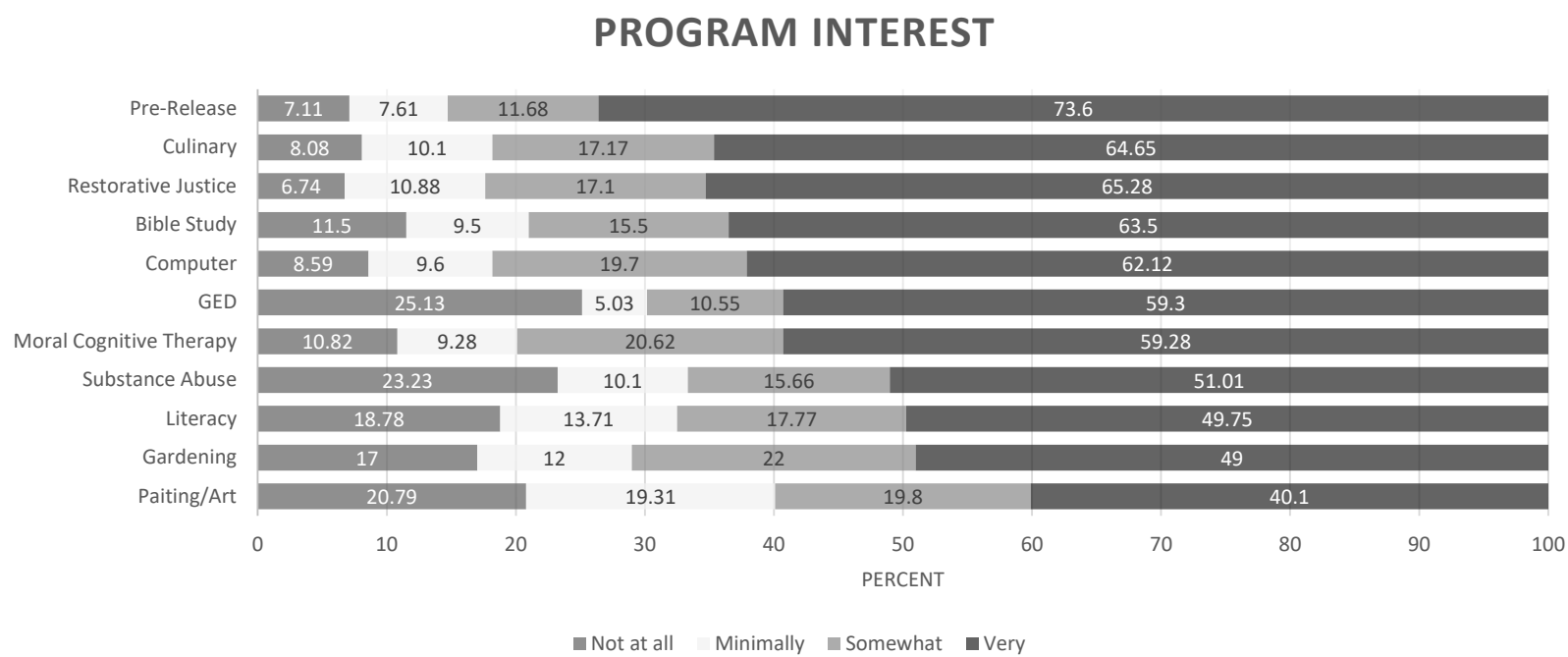

\section{PROGRAM INTEREST}

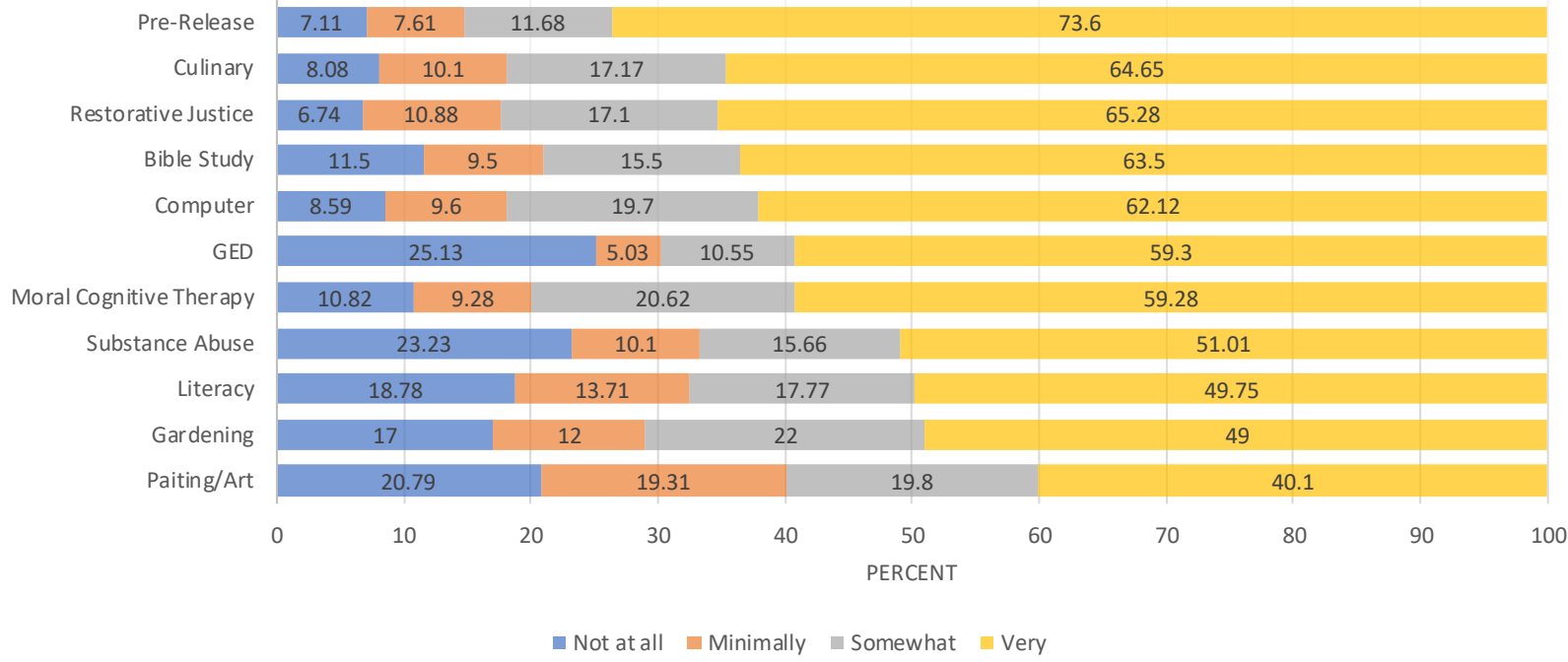


Table 3 .

Cross Tabulation of Inmate Interest in Pre-Release Programs by Total Length of Sentence

\begin{tabular}{lcccc}
\hline & \multicolumn{4}{c}{ Interest in Pre-Release Programs } \\
\cline { 2 - 5 } Sentence Length & $\begin{array}{c}\text { Not at all } \\
\text { Interested }\end{array}$ & $\begin{array}{c}\text { Minimally } \\
\text { Interested }\end{array}$ & $\begin{array}{c}\text { Somewhat } \\
\text { Interested }\end{array}$ & Very Interested \\
\hline Less than 10 years & 11.11 & 5.56 & 16.67 & 66.67 \\
$10-19$ years & 9.38 & 3.13 & 3.13 & 84.38 \\
20 years - Life & 6.12 & 8.84 & 12.93 & 72.11 \\
Total & 7.11 & 7.61 & 11.68 & 73.60 \\
\hline
\end{tabular}

$\mathrm{X}^{2}=5.32, \mathrm{df}=6, p=.50$; Note. Presented as row percentages. 
Figure 2.

Comparing Percent of Inmates Reporting “Very Interested” in program \& Percent Participated



Comparing "Very Interested" \& Percent Participated




Table 4.

Descriptive Statistics of Types of Reported Barriers to Prison Program Participation

\begin{tabular}{lcc}
\hline Barrier & Mean & SD \\
\hline Prison conditions/circumstances & 2.82 & 1.17 \\
Pre-requisites to get into program & 2.30 & 1.19 \\
Lack of program variety & 2.32 & 1.15 \\
Program requirements & 2.13 & 1.20 \\
Program not offered often enough & 2.13 & 1.18 \\
Lack of space in program & 1.99 & 1.07 \\
Amount of time to complete program & 1.88 & 1.07 \\
Other* & 2.62 & 1.51 \\
\hline
\end{tabular}

Note: * sample size for this variable only 88 
Table 5

Correlation Matrix of Program Participation and Barriers

\begin{tabular}{|c|c|c|c|c|c|c|c|c|}
\hline \multicolumn{2}{|c|}{ Variable } & 1 & 2 & 3 & 4 & 5 & 6 & 7 \\
\hline 1 & Program Participation Index & & & & & & & \\
\hline 2 & Prison conditions/circumstances & .06 & -- & & & & & \\
\hline 3 & Pre-requisites to get into program & $-.17^{* *}$ & $.34^{* * *}$ & -- & & & & \\
\hline 4 & Lack of program variety & .01 & $.31^{* * *}$ & $.31^{* * *}$ & -- & & & \\
\hline 5 & Program requirements & $-.12^{*}$ & $.35^{* * *}$ & $.54^{* * *}$ & $.35^{* * *}$ & --- & & \\
\hline 6 & Program not offered often enough & $-.18^{* *}$ & $.33^{* * *}$ & $.39^{* * *}$ & $.42^{* * *}$ & $.29^{* * *}$ & -- & \\
\hline 7 & Lack of space in program & $-.23^{* * *}$ & $.29^{* * *}$ & $.29^{* * *}$ & $.40^{* * *}$ & $.38^{* * *}$ & $.45^{* * *}$ & -- \\
\hline 8 & Amount of time to complete program & -.06 & $.31^{* * *}$ & $.31^{* * *}$ & $.32^{* * *}$ & $.32^{* * *}$ & $.27^{* * *}$ & $.41^{* * *}$ \\
\hline
\end{tabular}

${ }^{*} p<.10 ;{ }^{* *} p<.05 ; *^{* * *} p<.01$ 
Table 6.

Qualitative Responses to Inmate Reported Barriers to Prison Programs

\begin{tabular}{|c|c|c|c|}
\hline Theme & Axial Codes & Open Codes & Count \\
\hline \multirow[t]{4}{*}{ Prison Conditions } & & & 62 \\
\hline & Lockdowns & $\begin{array}{l}\text { Constant lockdowns; we are on lockdown a lot; institution lockdowns } \\
\text { stop all education; facility often on lockdown }\end{array}$ & 49 \\
\hline & Movement/count & $\begin{array}{l}\text { Controlled movement; no movement; limited movement; movement rule; } \\
\text { Counts get messed up all the time; count issues; count times }\end{array}$ & 11 \\
\hline & Security & Security issues; security; security schedule; lack of adequate security & 7 \\
\hline \multirow[t]{3}{*}{ Staffing Issues } & & & 29 \\
\hline & Lack of Staff & $\begin{array}{l}\text { Lack of staff; not enough staff; staff needed; short of staff; staff shortage; } \\
\text { staffing }\end{array}$ & 15 \\
\hline & Staff issues & Staff mentality; staff doesn't care; lack of caring & 7 \\
\hline \multirow[t]{6}{*}{ Eligibility/Access } & & & 60 \\
\hline & Charges/crime & Charges; Certain charges prohibited; prison charge & 7 \\
\hline & Life Sentence & $\begin{array}{l}\text { Life sentence prevents participation; life sentence put on back burner; life } \\
\text { sentences can't participate }\end{array}$ & 11 \\
\hline & Time left & $\begin{array}{l}\text { Amount of time left; only offered to short timers; limited to persons with } \\
5 \text { years or less; minimum sentence left to serve }\end{array}$ & 29 \\
\hline & Selection & $\begin{array}{l}\text { Must know somebody; not fairly allowed to all inmates; buddy system; } \\
\text { favoritism }\end{array}$ & 17 \\
\hline & Pre-requisites & $\begin{array}{l}\text { Need GED; pre-requisites for programs; must have experience; only } \\
\text { choose experienced people }\end{array}$ & 12 \\
\hline \multirow[t]{4}{*}{ Program Quality Issues } & & & 17 \\
\hline & Teacher/instructor & $\begin{array}{l}\text { Offer little help; lack experience; very poor people skills; not qualified; } \\
\text { don't care; taught by inmates }\end{array}$ & 10 \\
\hline & quality & Quality and effectiveness & 2 \\
\hline & Structure/time & Lack of structure; not long enough; classes cancelled; time requirements & 7 \\
\hline \multirow[t]{4}{*}{ Variety/Availability } & & & 41 \\
\hline & Lack of Space/Availability & $\begin{array}{l}\text { Lack of space; wait list; availability; not enough to accommodate all; not } \\
\text { enough room }\end{array}$ & 13 \\
\hline & Lack of variety & Lack of variety; not enough variety; limited choices & 17 \\
\hline & Vocational/trade & Vocational school; job placement; career classes & 9 \\
\hline
\end{tabular}

Note: Many inmates reported multiple barriers. 